\title{
INFORMATION THE TRANSFORMATION OF PUBLIC ADMINISTRATIONS: THE CASE OF E-HOUSEKEEPER IN TAIWAN
}

\author{
Su-Houn Liu, Chung Yuan Christian University, vandy@mis.cycu.edu.tw \\ Tsang-Yao Chen, Chung Yuan Christian University, PoloChen@cycu.edu.tw \\ Hsiu-Li Liao, Chung Yuan Christian University, wenlly.liao@msa.hinet.net
}

\begin{abstract}
Many researchers have explored how to better deploy public services over the Internet. Starting year 2006, the Taiwan government has initiated a new generation of its e-Government public service information infrastructure- - the i-Government project. In May 2007, e-Housekeeper, the first application of i-Government implementation is deployed. Current survey results show that e-Housekeeper has drastically increased the willingness of use and satisfaction rate of the online public service users. With the integrated, standardized, and active online public services, the i-Government project is seen to have the potential to transform public administrations in Taiwan.
\end{abstract}

Keywords: e-Government, On-line Service Platform, Public Service

\section{INTRODUCTION}

As a leading country in ICT (information and communications technology), the Taiwan government has devoted to the use of ICT in providing e-government services to the general public. The major e-government initiatives have been part of the comprehensive national ICT infrastructure programs such as the e-Taiwan starting 1998 [4], followed by m-Taiwan and u-Taiwan (or Ubiquitous Network Society, UNS) programs.

The e-Government project, as part of e-Taiwan, was initiated in 1998 as an effort to establish a gateway system with the automation of various governmentto-citizen services and the establishment of administrative applications within the government systems. Online public services offered to the citizens were constructed (for example, the popular eTaxation with income information automated with a security card measure) and administrative-use applications were created (such as the electronic document exchange system and government sourcing and procurement system).
Based on the experience from the e-Government project early implementation, the government has expanded the online public services in the second phase of the project. The concept of Online Services is central in this expansion stage to create a serviceoriented government. All online public services are integrated into higher level clusters. As seen in the framework of measures, the second phase of eGovernment is conceptualized into services provision, information sharing, information system computerization, and the improvement of infrastructure [2], [7].

The Taiwan e-Government project has since received much attention from the recognitions such as the Brown University E-Government Annual Report. During the past years, Taiwan has been ranked as number one in 2004 and 2005 and number 2 in 2006. According to a survey in 2006, almost 100 percent of the Internet users have used at least one eGovernment online services [4]. The overall satisfaction rate to e-Government is $82 \%$, which is higher than the average $70 \%$ satisfaction rate toward traditional government services.

However, as Accenture indicates on its e-government evaluation report [3], there is a trend of slowingdown in the progress of e-government development in advanced countries. The e-Government of Taiwan is facing some challenges for its further development.

First of all, despite of the overall high satisfaction rate, stratified analysis shows that the well-educated urban adult users are the most unsatisfied group of eGovernment users. These groups are heavy users of online services and thus the most important clients of the e-Government services. The government of Taiwan believes that, this fact shows that its current e-Government services have not yet reached the true potential of online public services.

Secondly, with the high usage percentage, research shows that users mostly look up public information online (35\%) and take part in the government-held events (34\%). Only $15 \%$ of the citizens use eGovernment for service processing [4]. Because 
online services are where e-government would create effectiveness, these figures show that the Taiwan e-
Government has not created the effectiveness as desired.

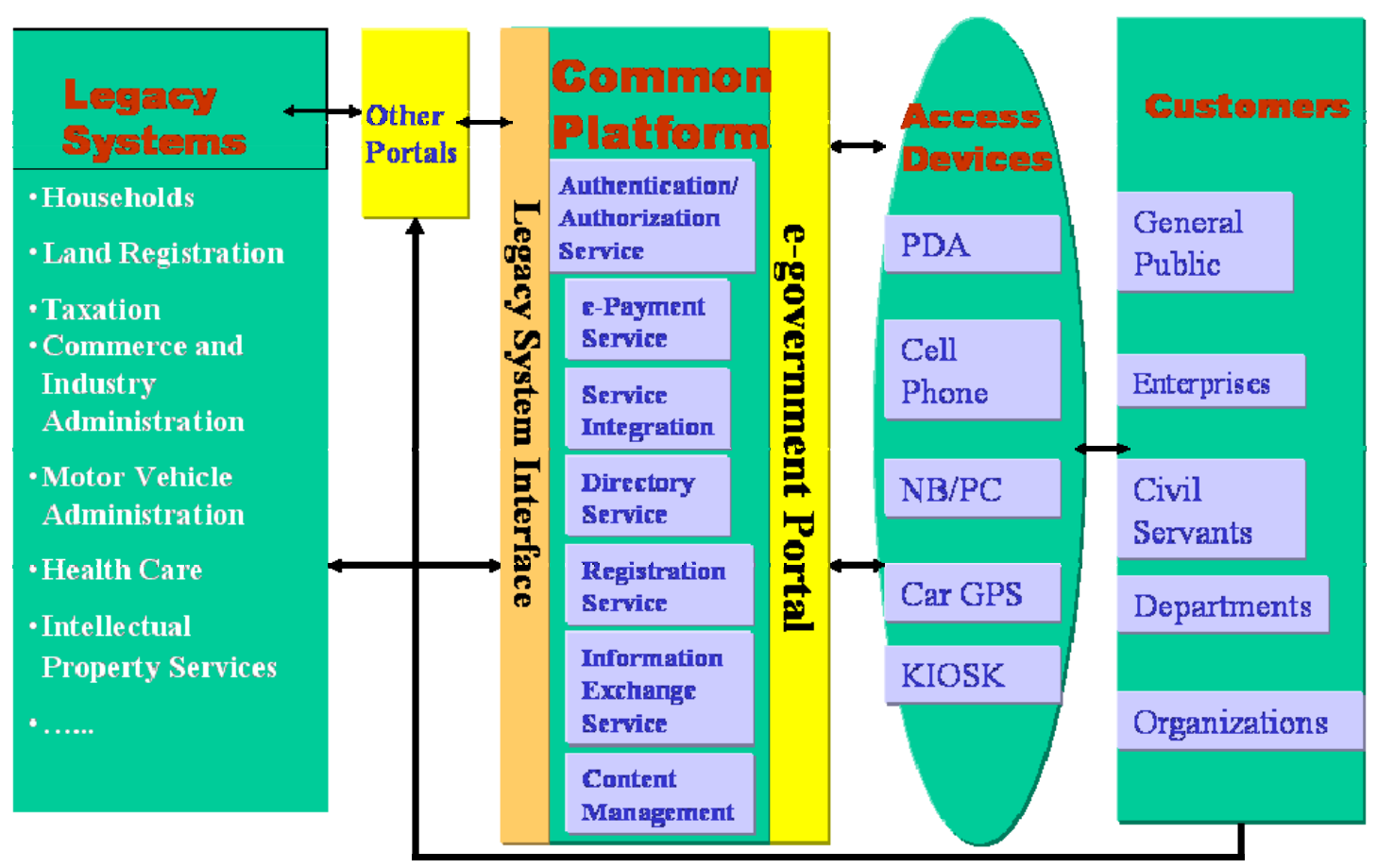

Figure 1. Service-Oriented E-Government Architecture

Thirdly, a small number of online public services receive most e-Government users. For example, the e-Taxation has a usage rate of $20.53 \%$ in its first year deployment in 2004 and is expected to reach over $50 \%$ in 2007. Yet most other online services such as the online traffic ticket payment system started in 1999, has a usage rate of less than $4 \%$ until 2006 , which is even lower than the payment made through the post office financial transaction service. This shows that, in Taiwan, "citizen-connected" is not a problem; rather, "service-connected through citizen" is the issue.

Over the years, Taiwan has put many public services online through the MyEGov (www.gov.tw) portal created in 2002 by the Research, Development and Evaluation Commission (RDEC). The eGovernment's MyEGov portal was meant to be the entry point for all online public services. It is designed to provide a focal place for the collection of all government information and services. However, since services on MyEGov are created independently by different government agencies, the scattered and passive services can not satisfy the high quality services demanded by citizens to reach the true effectiveness of e-government, especially when more than 1000 new public services are now created annually in Taiwan. Thus, when more services are offered, the citizens have to go through the learning curve to use different applications. This has limited the e-Government's network externalities. Therefore, the need to create a single platform so citizens are able to use the services easily and fully is seen and the i-Government project is proposed and developed.

The new generation of e-Government: the integratedGovernment, or "i-Government", is the continuity of the e-Government project with a different service paradigm. The " $\mathrm{i}$ " in $\mathrm{i}$-Government characterizes this new stage of e-Government implementation. The $\mathrm{i}$ stands for five characteristics of Taiwan's new egovernment services to be "Integrated" and to provide "Individualized" services "Instantly" with "Innovative” approaches.

The 5 I's are realized in the framework of the iGovernment's "reverse" service flow. In the iGovernment project, the online public services will reach out to the users for communications and the government agencies will be able to focus on the internal processing [6]. The services are divided into three sections: e-Housekeeper for service provision to the general public, the e-Business to manage the G2B 
activities, and e-Governance for internal and cross-

departmental governmental operations (Figure 2).

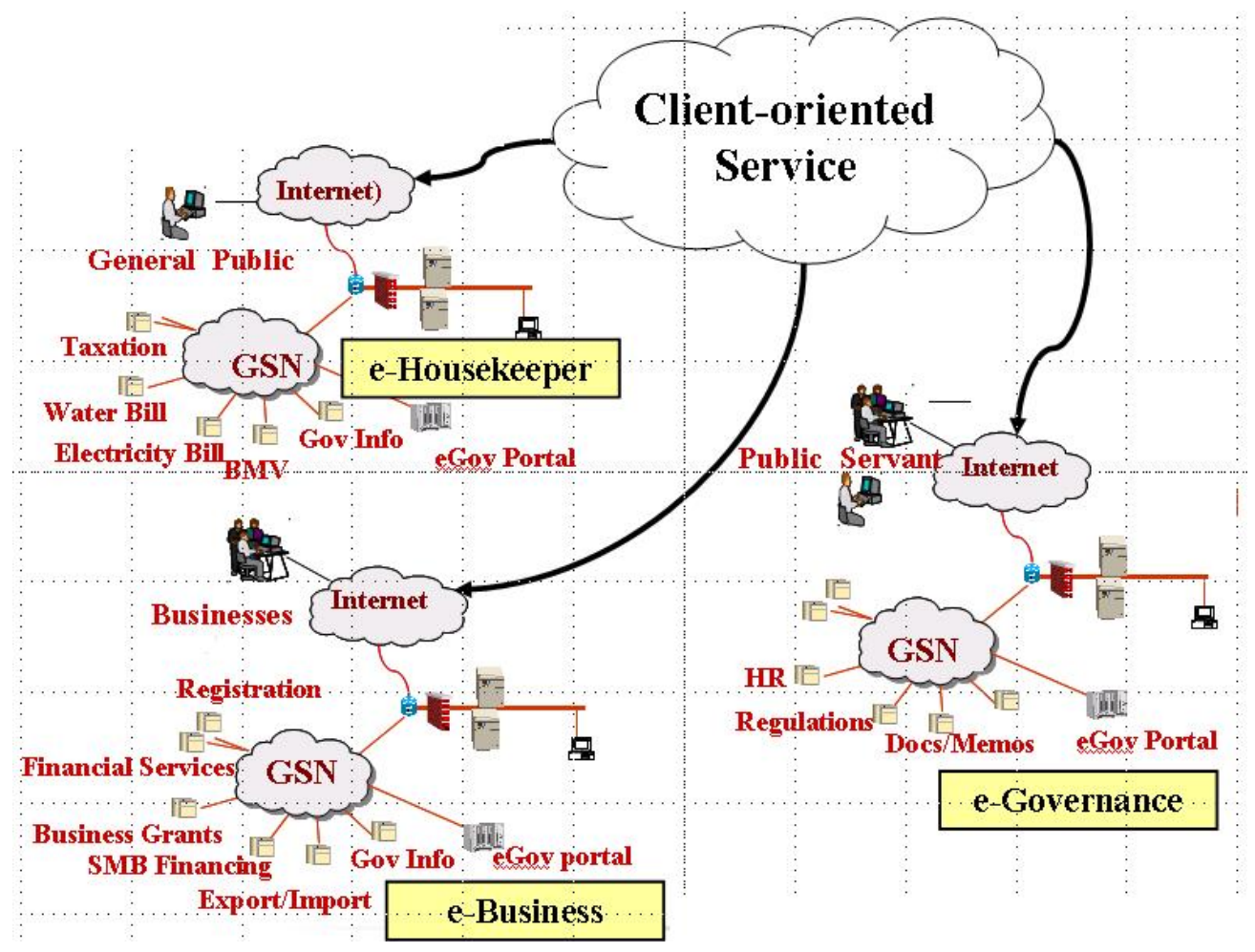

Figure 2. The Three Main Components Of I-Government

E-Housekeeper is the first application launched in the implementation of i-Government [5]. From the survey on the first month of implementation, this client-oriented, end-to-end service online public service has shown great potential and may become another "killing app" for e-government development. With the network effect foreseen, e-Housekeeper is expected to be the first application in transforming the e-government public administration in Taiwan.

\section{E-HOUSEKEEPER}

\section{What is e-Housekeeper}

To an end user, e-Housekeeper is an MSN Instant Messenger-like application that starts with the computer system and stays in the system tray of the Windows operation environment. It gives personalized message on subscribed services which lead to the online public services provided through various governmental agencies. To use eHousekeeper, the user has to go online to download the client software. The client uses the MyEGov portal membership so all current e-Government users can log in to start the service easily. Users can choose the services they desire for e-Housekeeper to notify. The e-Housekeeper started with 7 notification services and has increased to 11 after one month. For example, in Figure 3, the user chooses water bill, parking fees, and BMV services. The yellow pop-up shows an unpaid parking charge pending. Upon the end of the payment period (system default as three days), a pink pop-up will show up to urge the user to process the payment before the deadline.

When the user sees a message, a click on the message will open a browser to show more information and directions for further online processing. As shown in Figure 4 , in Step 1 the user clicks on the green message. In Step 2 detailed information about this parking fee charge (such as time, place, and fee schedule, etc...) are made available. After verifying the charge, the user can directly pay for it online in Step 3.

\section{The e-Housekeeper Architecture}

The e-Housekeeper consists of three major components: the client software to connect to the user 
(Access Layer), the server system that provides the value-add service (Web Layer), and the gateway system connecting service processing from various online public service providing agencies (Service Layer).

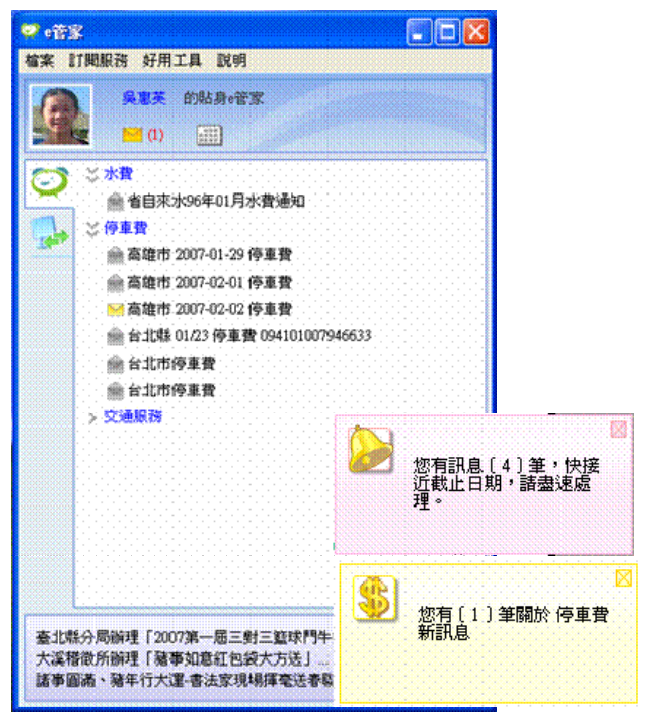

\section{The Access Layer}

With the assistance from Microsoft Taiwan, the eHousekeeper client software is intentionally designed to use an MSN-like interface for the reason that MSN Messenger is the most popular IM software in Taiwan. Such interface therefore would considerably reduce the learning curve and raise the client's willingness to use. The client software includes the configurable main window interface for message notification display, a click-to-open calendar, and a message viewing area at the bottom (serving as a public service bulletin board). The users use the main window (Figure 5) to subscribe services and to configure how the services are provided (for example, weather the message is to be sent simultaneously through SMS or email). The message display area of the main window shows the notifications from subscribed services. The notification and events related to the message (e.g., the deadline for the payment) will be automatically recorded to the user's personal calendar (Figure 6).

Figure 3. E-Housekeeper Message Window And Alert Pop-Up

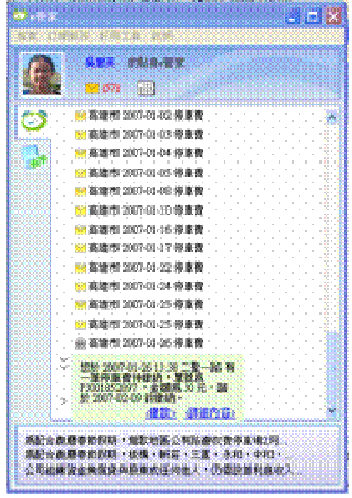

Step 1. Notification

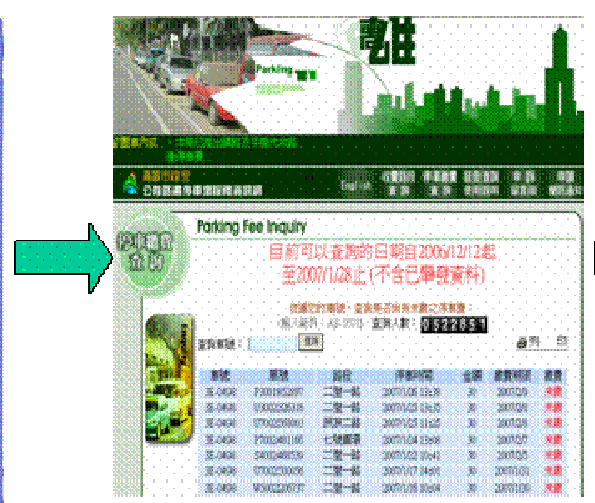

Step 2. Inquiry

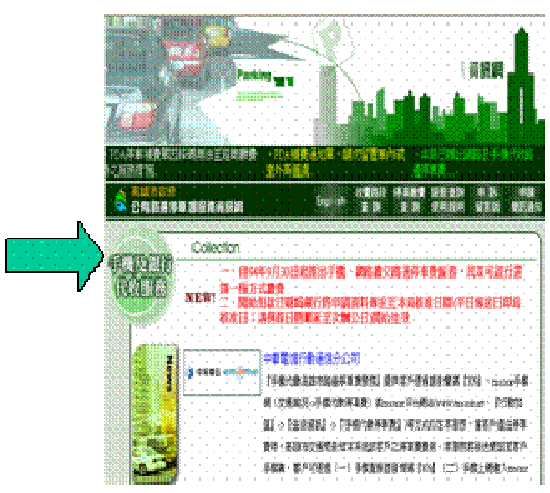

Step 3. Payment

Figure 4. On-line Process Of Paying a Parking Fee In E-Housekeeper 


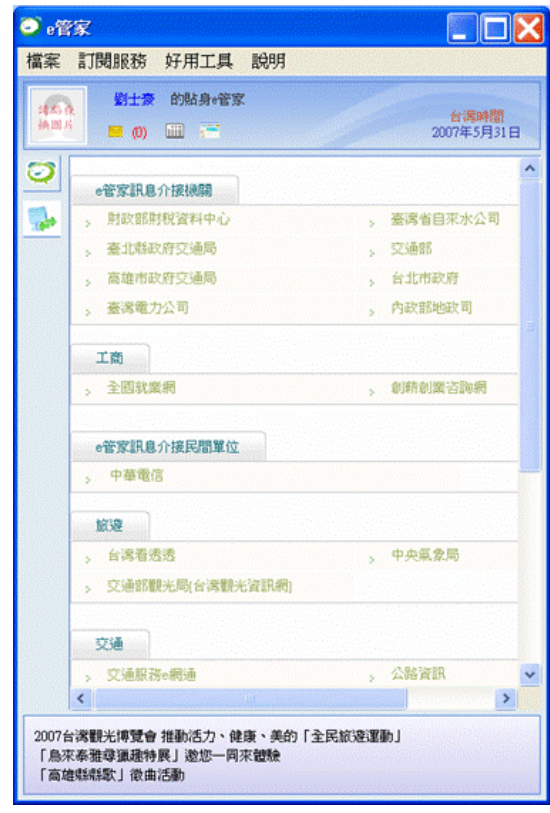

Figure 5. Service Subscription and Configuration Window

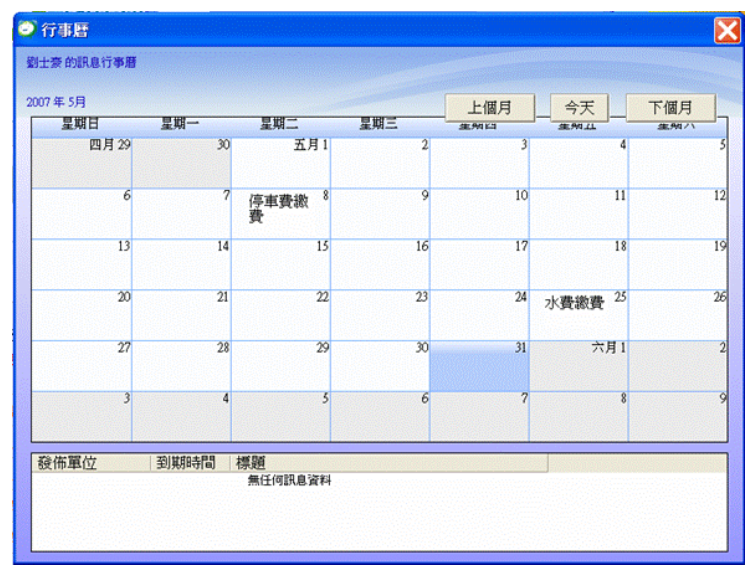

Figure 6. Personal Calendar Window

\section{Web Layer}

The major function of the Web Layer is to organize the government's online services from all government agencies according to standardized operation logic. In the past, government agencies at all levels work hard to provide online version of their service processing. However, the operational interfaces are usually decided by their website designers. Therefore, for one service such as applying certification paper, there would be different processing flows from different agencies. Sometimes even when applying the same type of certification (such as a real estate property certification) there will be different processing flows and interface across different local government offices with different functions (e.g., the availability of credit card payment system). The Web Layer periodically gathers the service notifications (such as payment notifications) and delivers them to the users. When the user did process on the message, the Web Layer manage the personal calendar and provide service by the user's request through the Service Layer (Figure 7). All the message delivery, reception, and service processing are recorded through the Web Layer to avoid inconsistency in the future.

\section{Service Layer}

The Service Layer is an application based on the 2005 e-Government Common Service Platform. The e-Government Common Service Platform is a service provision platform constructed using Web Services technologies. It was implemented in order to gradually integrate the online services on the public service websites with Web Services technologies. Starting from 2007, the Taiwan government begins to implement a Government Directory Service (GDS) to establish a single coding system for all public services. All new online public services are required to have a single categorization code to provide public services on the e-Government Common Service Platform. The Service Layer can then call the services from the platform to provide online public services to the users (Figure 8) and thus make the services standardized. 




Figure 7. The Web Layer

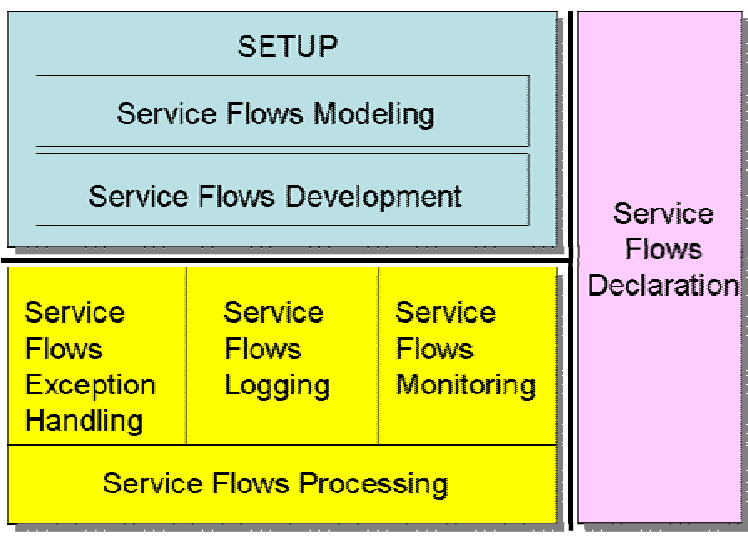

Figure 8. The Service Layer Architecture

\section{CURRENT STATUS AND FUTURE WORK}

In Taiwan, the MyEGov central e-government portal was created as the e-Government project's hub of all online public services. The new i-Government takes one step further to integrate the services with eHousekeeper as the first application.

As the first system toward the complete iGovernment project, the e-Housekeeper implementation started in early 2006. After a development period of 14 months, the protocol system was completed in April 2007. The system starts with 7 services (11 services in May) including online services such as traffic services charges, water and electricity billing, parking charges. These services are deemed as priority for development after surveying the general public and decided to be the most desired services by the general public. With an active and integrated application providing desired services, e-Housekeeper is expected to become a killing app in Taiwan's e-government implementation.

At the end of April 2007, e-Housekeeper starts its first year field test. In the first month, there are 10,000 registered users participating in the test. Over $55 \%$ of the users subscribed all 7 services. Up to May $20^{\text {th }}$, most users have used more than one online service through the e-Housekeeper. It is noteworthy that, for most subscribed services, over $2 / 3$ are what the users have never used before. On May 15 another four real estate related registrations and tax processing services, which previously have their online service usage rate lower than $10 \%$, were put on the e-Housekeeping. After two weeks, almost all registered users (93\%) have subscribed at least one of these four new services. It is evident that eHousekeeper platform can make the online public services outreach to its potential users far more effective than the passive MyEGov portal.

The trial of the e-Housekeeping also reveals that it can be a cost-effective way to provide standardized online public services. The e-Housekeeper provides great potential on saving processing cost both on the government and the citizens. For online public service provisions, for example, when zoning information are made available along with land data, people can access the needed information online for preparing the purchasing and selling of real estates, which has become quite a demanded service since in Taiwan over $85 \%$ percent of the residents own their 
houses. Before the e-government services are in place, the residents would have to go to different government offices to gather related information while now they can enjoy the convenience of the new technologies. The cost-effectiveness of e-government service provision is evident with proper use of technologies.

With the seemingly promising future, however, the eHousekeeper trial does reveal possible barriers in the same time for its future development. The first is structure accountability. Traditionally, each government agency provides services to the general public directly, the service satisfaction would therefore reflect on the performance review system of the agency. E-Housekeeper, by providing a single service platform, could take away this source of performance information since it has become the connection between the governmental agencies and the general public. Especially for the elected officials, the accountability issue could become a possible implementation barrier for i-Government.

Another possible barrier is information-overflow: the dilemma in balancing between user attention and volume of information provided. On one hand, the more information e-Housekeeper provides, the larger the user base is. On the other hand, too much information will cause information-overflow and in turn reduce the willingness of the users or potential users in using e-Housekeeper. Theoretically, users would subscribe to the information needed to avoid the dilemma. However, the trial finds that, the participating governmental agencies tend to send more messages they considered necessary than the subscribers. The subscribers, on the other hand, tend to subscribe more messaging services than they need. This is resulting complaints to e-Housekeeper for information-overflow. Although this might be a short term issue of adjusting using habit, it deserves careful observation. As for the possible needs to adjust the eHousekeeper system structure and operational procedures, a formal review will necessarily be conducted to explore the needs at the end of the trial.

\section{CONCLUSIONS}

As a leader in e-government development and services, Taiwan has strived to get through the bottleneck to provide end-to-end processing online public service. Taiwan's i-Government project, in particular the first integrated application eHousekeeper, is one step further toward turning the egovernment services from passive provision into active “push”. Citizens will enjoy the single platform of active, integrated and standardized service delivery to their computer just like a housekeeper to their door. This will bring the administrative effectiveness of public service into the next level: the effectiveness of the general public rather than the governmental agencies. While in its first stage of implementation, Taiwan has witnessed this switch of paradigm coming in place.

\section{REFERENCES}

1. Ebrahim, Z. and; Irani, Z. (2005). E-government adoption: architecture and barriers. Business Process Management Journal, 11(5), 589-611.

2. Lin, Y.C. (2006). e-Government in Taiwan: Status and Relevant Experiences. Country Report on GOVTEC2006.

3. NICI. (2007). Canada Leads World in EGovernment on Accenture Survey. http://www.nici.nat.gov.tw/content/application/ni ci/generala/guest-cnt-

browse.php?cntgrp_ordinal $=1002006100110003$ \&cnt_id=752.

4. RDEC (2006). 2006 Government e-Service Survey.

5. RDEC (2005). Request for Proposal: eHousekeeper.

6. Sung, Y.H. (2006). From the e-Government to the i-Government. 2006 Digital Cities Convention Taipei.

7. Sung, Y.H., Lin, Y.C. and Chen, S.C. (2006). eGovernment in Taiwan: Yearly Report. Country Report on 40th ICA Conference, Guadalajara Mexico.

8. Torres, L., Pina, V. and Royo, S. (2005). Egovernment and the transformation of public administrations in EU countries. Online Information Review, 29(5), 531-553. 